\title{
An implantable turbomechanical cavopulmonary assist device: Guarded optimism for harnessing the river to do upstream work
}

\author{
David P. Bichell, MD
}

From the Vanderbilt University Medical Center, Monroe Carell, Jr Children's Hospital, Nashville, Tenn

Disclosures: Author has nothing to disclose with regard to commercial support.

Received for publication March 11, 2018; accepted for publication March 15, 2018

Address for reprints: David P. Bichell, MD, Vanderbilt University Medical Center, Monroe Carell, Jr Children's

Hospital, 2200 Children's Way, Nashville, TN 37232 (E-mail: david.bichell@ vanderbilt.edu).

J Thorac Cardiovasc Surg 2018;156:302-3

$0022-5223 / \$ 36.00$

Copyright $($ c 2018 by The American Association for Thoracic Surgery

https://doi.org/10.1016/j.jtcvs.2018.03.052

Approximately 1700 Fontan procedures are performed annually in the United States, and 20-year survival is close to $90 \%$. $^{1,2}$ The inevitable price paid for the absent prepulmonary ventricle is cardiac and extracardiac organ disease, a growing health burden in a population that is growing in number and age. ${ }^{1,2}$ The development of mechanical cavopulmonary support for the failing Fontan, or more importantly, support suitable for early intervention to preempt Fontan failure altogether, is an ambitious but necessary pursuit. The most vexing challenges to a successful device today remain thrombosis and power source.

Pekkan and colleagues ${ }^{3}$ propose an ingenious new look at a power source, heretofore hidden in plain view, a solution that purports to eliminate the enormous problems of battery power, drive line, and heat dissipation. The prototype is an implantable turbomechanical pump that extracts work from the systemic ventricle through an aorto-atrial turbine to power an integrated impeller pump in the cavopulmonary circulation. The device evokes the design of Marcus Vitruvius Pollio, Roman engineer of the first century $\mathrm{BC}$, of a waterlifting machine that extracts work from a river-driven turbine to power an integrated Archimedes pump to carry water uphill.

Fontan failure does not mean systemic ventricular failure. At long-term follow-up, most Fontans have normal systemic ventricular function and the extraction of systemic ventricular work to augment the pulmonary circuit is an appealing and logical concept. ${ }^{1}$ The authors theorize of their device that even if power transmission efficiency is only $50 \%$, and the aorto-atrial turbine steals only $5 \%$ of aortic flow, up to $5 \mathrm{~mm} \mathrm{Hg}$ pressure diminution in the venous circulation is possible.

Hopeful for success as a solution to the power hurdle, thrombosis still looms to challenge this innovative prototype. The model introduces 2 indwelling devices in the bloodstream, and therefore 2 potential sites for

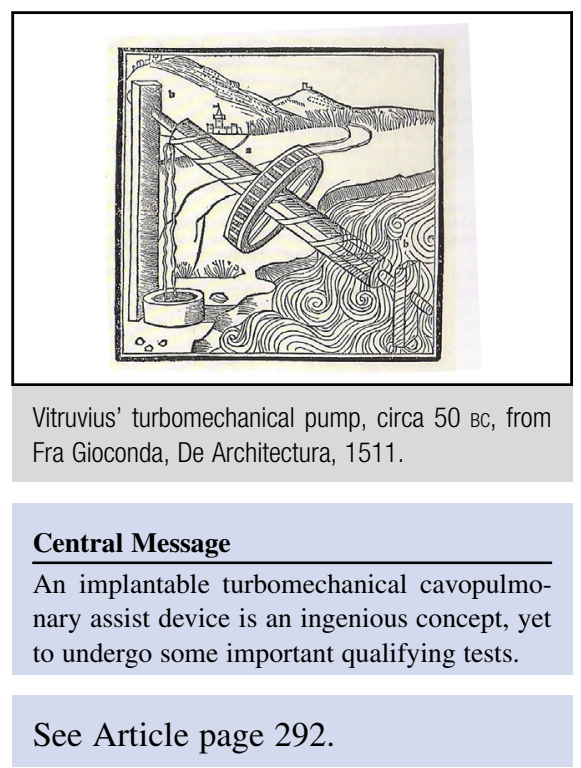

thromboembolic problems. Aorto-atrial shunt thrombosis would also mean a stasis of the cavopulmonary impeller, and failure of one is failure of both.

Giridharan and colleagues, ${ }^{5}$ refining an axial viscous impeller cavopulmonary assist device, note the importance of a nonobstructive impeller in the event of drive failure, where a modest gradient could herald catastrophic cardiovascular failure. The Pekkan prototype, with the impeller in passive rotation or at full stop, has a resultant 3- to 5 -mm venous circuit gradient measured in vitro. At pump failure, venous blood flow navigates through static impeller blades to a route of egress perpendicular to the axis of inflow. Important work remains in ensuring that this arrangement does not precipitate kinetic power loss or thrombosis during periods of low or static impeller rotation, situated in a passive flow system as sensitive as the Fontan circuit.

Power storage and transfer are theoretically solved by this elegant prototype that requires no drive line and no battery by harnessing the available power of the nearby systemic river to do work upstream. The in vitro model shows proof of concept. Many steps remain before translation to a working biologic system, but there is a big interest in seeing this innovative concept carried to in vivo testing. 


\section{References}

1. Anderson PAW, Sleeper LA, Mahony L, Colan SD, Atz AM, Breitbart RE, et al. Contemporary outcomes after the Fontan procedure: a pediatric heart network multicenter study. J Am Coll Cardiol. 2008;52:85-98.

2. Kotani Y, Kasahara S, Fujii Y, Yoshizumi K, Oshima Y, Otsuki S, et al. Clinical outcome of the Fontan operation in patients with impaired ventricular function. Eur J Cardiothorac Surg. 2009;36:683-7.

3. Pekkan K, Aka IB, Tutsak E, Emek E, Balim H, Lazoglu I, et al. In vitro validation of a self-driving aortic-turbine venous-assist device for the Fontan patients. J Thorac Cardiovasc Surg. 2018;156:292-301.e7.

4. Giacondo F. Vitruvius, De Architectura. Venice; 1511.

5. Giridharan GA, Koenig SC, Kennington J, Sobieski MA, Chen J, Frankel SH, et al Performance evaluation of a pediatric viscous impeller pump for Fontan cavopulmonary assist. J Thorac Cardiovasc Surg. 2013;145:249-57. 